\title{
Power management in co-phase traction power supply system with super capacitor energy storage for electrified railways
}

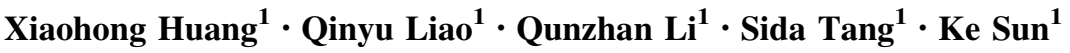

Received: 19 November 2019/Revised: 12 February 2020/Accepted: 13 February 2020/Published online: 28 February 2020

(C) The Author(s) 2020

\begin{abstract}
Increasing railway traffic and energy utilization issues prompt electrified railway systems to be more economical, efficient and sustainable. As regenerative braking energy in railway systems has huge potential for optimized utilization, a lot of research has been focusing on how to use the energy efficiently and gain sustainable benefits. The energy storage system is an alternative because it not only deals with regenerative braking energy but also smooths drastic fluctuation of load power profile and optimizes energy management. In this work, we propose a co-phase traction power supply system with super capacitor (CSS_SC) for the purpose of realizing the function of energy management and power quality management in electrified railways. Besides, the coordinated control strategy is presented to match four working modes, including traction, regenerative braking, peak shaving and valley filling. A corresponding simulation model is built in MATLAB/ Simulink to verify the feasibility of the proposed system under dynamic working conditions. The results demonstrate that CSS_SC is flexible to deal with four different working conditions and can realize energy saving within the
\end{abstract}

Xiaohong Huang

Huangxh_ee@swjtu.edu.cn; hxhxj924@163.com

Qinyu Liao

Qyliao_abc@126.com

Qunzhan Li

Lqz3431@263.net

Sida Tang

402998593@qq.com

Ke Sun

1731401192@qq.com

1 School of Electrical Engineering, SouthWest Jiaotong University, Chengdu, China

allowable voltage unbalance of $0.008 \%$ in simulation in contrast to $1.3 \%$ of the standard limit. With such a control strategy, the performance of super capacitor is controlled to comply with efficiency and safety constraints. Finally, a case study demonstrates the improvement in power fluctuation with the valley-to-peak ratio reduced by $20.3 \%$ and the daily load factor increased by $17.9 \%$.

Keywords Electrified railway - Co-phase traction power supply system · Energy storage $\cdot$ Peak shaving · Valley filling $\cdot$ Power quality $\cdot$ Super capacitor

\section{List of symbols}

$w$

$p_{\mathrm{L}}$

$p_{\mathrm{H}}$

$p_{\text {load }}$

$S_{\mathrm{c}}$

$S_{\mathrm{L}}$

$S_{\mathrm{H}}$

$p_{\mathrm{s}}$

$p_{\mathrm{sc}}$

$v_{\mathrm{a}}, v_{\mathrm{b}}, v_{\mathrm{c}}$

$V_{\mathrm{a}}, V_{\mathrm{b}}, V_{\mathrm{c}}$

$I_{\mathrm{a}}$

$\varphi_{\mathrm{a} 1}$

$i_{\mathrm{a}}, i_{\mathrm{b}}, i_{\mathrm{c}}$

$i_{\mathrm{ca}}, i_{\mathrm{cb}}, i_{\mathrm{cc}}$

$i_{\mathrm{a} 1}, i_{\mathrm{b} 1}, i_{\mathrm{c} 1}$

$v_{\mathrm{ab}}$

$i_{\text {load }}$
Electric energy

Power lower limit in load power optimization Power upper limit in load power optimization Actual load power

State of charge of super capacitor

Lower limit of state of charge of super capacitor Upper limit of state of charge of super capacitor Grid output power

Absorbing power of super capacitor

Three-phase voltages of the secondary side of transformer

Root-mean-square value of $v_{\mathrm{a}}, v_{\mathrm{b}}$ and $v_{\mathrm{c}}$, respectively

Root-mean-square value of secondary winding current

Phase angle of $I_{\mathrm{a}}$

Three-phase currents of the secondary side of transformer

Three-phase compensation currents

Positive sequence components of currents

Line voltage

Load current 


\begin{tabular}{|c|c|}
\hline$i_{\alpha}, i_{\beta}$ & $\begin{array}{l}\text { Current values in } \alpha \beta 0 \text { stationary reference } \\
\text { frame }\end{array}$ \\
\hline$i_{d}$ & $\begin{array}{l}\text { DC component of current in } d q 0 \text { rotating } \\
\text { reference frame }\end{array}$ \\
\hline$i_{\mathrm{Ld}}$ & DC component output of low-pass filter \\
\hline$i_{\alpha \mathrm{f}}, i_{\beta \mathrm{f}}$ & $\begin{array}{l}\text { Expected currents in } \alpha \beta 0 \text { stationary } \\
\text { reference frame }\end{array}$ \\
\hline$i_{\text {apf }}, i_{\text {bpf }}, i_{\mathrm{cpf}}$ & $\begin{array}{l}\text { Expected currents of the secondary side of } \\
\text { transformer }\end{array}$ \\
\hline$i_{\mathrm{pa}}, i_{\mathrm{pb}}, i_{\mathrm{pc}}$ & $\begin{array}{l}\text { Driving currents of PWM (pulse width } \\
\text { modulation) }\end{array}$ \\
\hline$i_{\text {ref }}$ & Expected current of super capacitor \\
\hline$i_{\mathrm{sc} \_f f}$ & Feedforward current of super capacitor \\
\hline$i_{\mathrm{sc}}$ & Super capacitor current \\
\hline$\Delta i_{\mathrm{sc}}$ & Current difference of super capacitor \\
\hline$\Delta i_{\mathrm{sc}}^{\prime}$ & PI value of $\Delta i_{\mathrm{sc}}$ \\
\hline$P_{\text {req }}$ & Design required power \\
\hline$v_{\mathrm{sc}}$ & DC side voltage of super capacitor \\
\hline$v_{\mathrm{dc}}$ & DC side voltage of PWM converter \\
\hline def & Given DC side voltage of PWM converter \\
\hline & Driving signal of PWM_boost \\
\hline$\Delta I$ & $\begin{array}{l}\text { PI adjustment of DC side voltage of PWM } \\
\text { converter }\end{array}$ \\
\hline & Daily load factor \\
\hline & Minimum load rate \\
\hline
\end{tabular}

\section{Introduction}

Inter-city travel demand is significantly growing [1]. Intensive railway traffic provokes concerns about energy efficiency and $\mathrm{CO}_{2}$ emissions. To build dynamic interaction between railway system and other traffic systems, following the development of Energy Internet, Traffic Energy Internet (TEI) [2] is put forward for the integration and centralization of transportation energy management. As the central component of the Traffic Energy Internet, the electrified railway system (ERS) has the great potential of energy recovery [2]. For the maximum utilization of regenerative energy, the concept of "generation-grid-loadstorage" system [2] was proposed to coordinate the dispatching system and energy management system. Up to now, extensive research has been carried out to improve the efficiency and speed of electrified railways. Regenerative braking $(\mathrm{RB})$ can be generally regarded as a process of transforming braking kinetic energy of a train during the deceleration into electrical energy to supply traction power [3]. Energy storage utilization and energy feedback utilization of regenerative braking energy have been widely applied in urban rail transit systems. González-Gil et al. [4] reported that RB can reduce energy-consuming by $10 \%$ to $45 \%$. In terms of the AC power supply, high load power, load volatility, complex working conditions and characteristic of bidirectional energy flow, energy storage and energy recycling for electrified railways were explored [5-7]. Li et al. [5] discussed using flywheel as an energy storage device and verified the feasibility of integrating flywheel and ERS. Interestingly, Hernandez and Sutil [6] demonstrated the viability of providing renewable power (RB energy and solar energy) charging services for electric vehicles parking at railway station. Reference [7] focused on MMC (modular multi-level converter)-based RB energy recovery device for ERS. However, it is known that regenerative braking energy will be wasted if no train starts or accelerates in the same power supply zone. As the allowable amount of regenerative power feeding back to utility grid is limited, it is usually dissipated by onboard braking resistors. Therefore, RB is environmental friendly because it reduces energy supply from grid and waste heat generation. To maximize the use of RB, timetables optimization [8-10] is studied with the best energy saving up to $30 \%$.

In reality, other economic factors should be considered. In China, the electricity charging standard includes the basic tariff and electricity tariff, of which the basic tariff in the two-part tariff system can be calculated by the transformer capacity or maximum demand depending on users' choice. The peak power of traction load directly influences both transformer capacity and maximum demand. Therefore, the economic benefits of RB can be considered as a long-term reduction in the ongoing cost of renewing railway infrastructure and a solution to the peak power. Hence, in order to utilize more regenerative energy and achieve smaller grid capacity, an energy storage system can play a key role as a transfer station. For power grid, introducing energy storage devices can mitigate the impacts caused by the volatility of load power when smoothing drastic fluctuation of load power profile.

Currently, there are many ways of integrating an energy storage device into ERS, such as onboard system, RPC (railway static power conditioner) system and hybrid PVbased (photovoltaic-based) system. In [11], the traction converter is connected to the super capacitor in parallel via the bidirectional DC-DC converter to store and release the RB energy. This work integrates the energy storage system with ERS, but arouses safety concerns about the placement and weight of the energy storage system. Chen et al. [12] developed a RPC with a super capacitor storage system, which can enhance the regenerative braking energy utilization, but they failed to solve the three-phase unbalance problem when super capacitors were discharging. Some 
research $[13,14]$ explored the application of photovoltaic generation technology in electrified railways, while other studies pay attention to power quality after a PV system accesses to ERS $[15,16]$.

When an energy storage system accesses to ERS, it is important to minimize its interference to the system. In contrast to DC locomotives, AC-DC-AC locomotives avoid low power factor and large harmonic content. However, the negative sequence that may influence system stability is one of the most pressing concerns in AC-DC$\mathrm{AC}$ locomotives. One possible solution is to equip a cophase traction power supply system with a suitable energy storage device on its DC side [17, 18]. Thus, the power quality can be considered and there is no need to use the neutral section device at the exit of the traction substation. However, expensive power electronic converters are employed in the aforementioned solutions [17, 18].

In this work, a modified co-phase power supply system with super capacitor energy storage (CSS_SC) is developed and its control strategy is proposed. It aims at optimizing power utilization and more importantly maintaining good power quality. The control strategy results in optimal

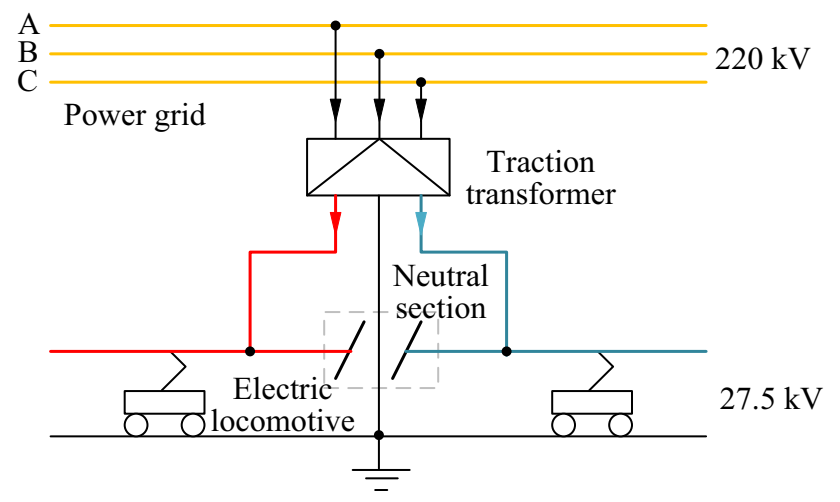

Fig. 1 Structure of standard ERS

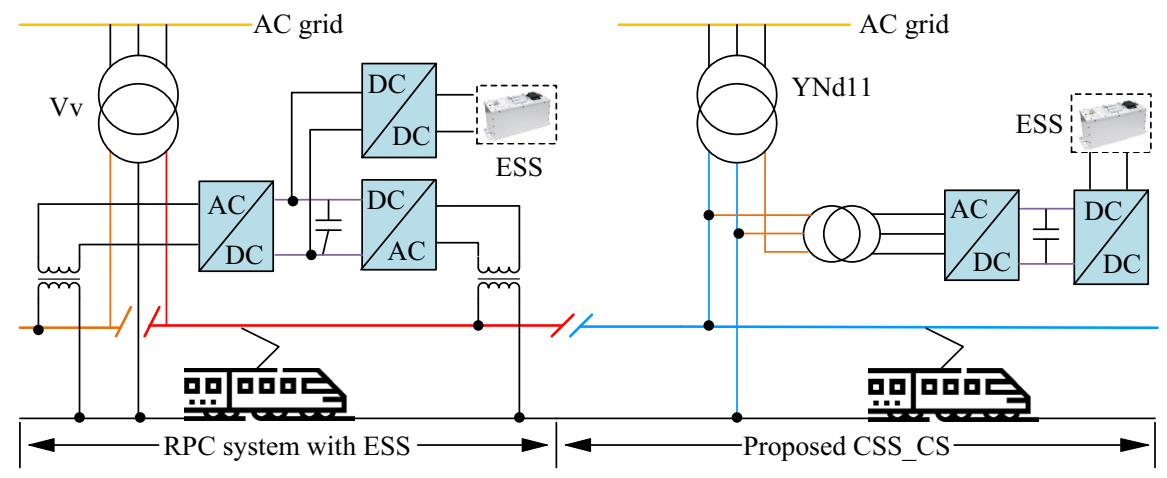

Fig. 2 Topology of CSS_SC and RPC system

charging/discharging profiles for storage components that guarantee highly efficient energy utilization. Moreover, it takes into account the current state of charge of energy storage. Energy management is suggested to guide the operation of the system to run in all kinds of working conditions.

The rest of the paper is arranged as follows. The next section introduces the system structure and advantages, as well as its working principle. In Sect. 3, the control strategy of CSS_SC is illustrated. Section 4 moves on to present the simulation results in MATLAB/Simulink, and a case study is provided. Finally, in Sect. 5, conclusions are summarized.

\section{System structure}

\subsection{Standard ERS structure}

The ERS has a mature structure as shown in Fig. 1. Newbuilt lines generally employ YNd11, Scott or $\mathrm{VV}_{\mathrm{V}}$ connecting transformers. The merits of traditional ERS structure are simplicity, robustness and low cost. However, in order to accommodate short-term high-power load, the design capacity of transformer is often surplus. Under normal circumstances, the load rate just reaches $20 \%-30 \%$, which means that the transformer capacity is wasted $[19,20]$. In the long term, as ERS absorbs nearby renewable energy source by ERSs, the power quality is hardly warranted when introducing the energy [21, 22], which is also a valuable research proposition. Hence, a comprehensive plan is needed.

\subsection{System schematic}

The shortcomings of RPC system have been briefly discussed in Sect. 1. In order to make the integration of ERS and ESS (energy storage system) more efficient, the 
connecting mode between transformer and AC-DC converter is slightly changed. As shown in Fig. 2, the proposed CSS_SC is relatively simple compared to RPC system. With this connecting mode, the negative sequence caused by high-power single-phase load can be compensated by the three-phase converter, and the energy can mutually transit between AC-DC converter and DC-DC converter.

In CSS_SC, network voltage (220 kV, nominal voltage) is stepped down to $27.5 \mathrm{kV}$ through the three-phase transformer of $\mathrm{YNd} 11$; then, catenary is powered by line voltage. The three-phase AC-DC converter is connected to the secondary winding of a three-phase transformer. Energy storage system can be accessed to the system via DC-DC converter which is connected to AC-DC converter on DC side. In this work, the AC-DC converter adopts three-phase bridge circuit and the DC-DC converter uses boost/buck DC-DC converter (see Fig. 3).

With the proposed solution, the neutral section devices can be removed at the exit of the traction substation. The distance of power supply is extended, and the speed of trains is increased. Moreover, introducing renewable energy can simplify the system structure.

\subsection{Analysis of working conditions}

\subsubsection{Load power diagram}

Figure 4 shows an actual traction load power profile of a feeder, which indicates the real time fluctuation of the traction load during 11:00 and 12:00. From Fig. 4, the inherent characteristics are revealed, i.e., the diurnal train operation exhibits periodicity and the power sharply fluctuates. The part of the curve above zero represents traction condition, while that below zero RB condition.

The electric energy is the integral of the traction power within the time interval $t_{1}$ to $t_{2}$ :

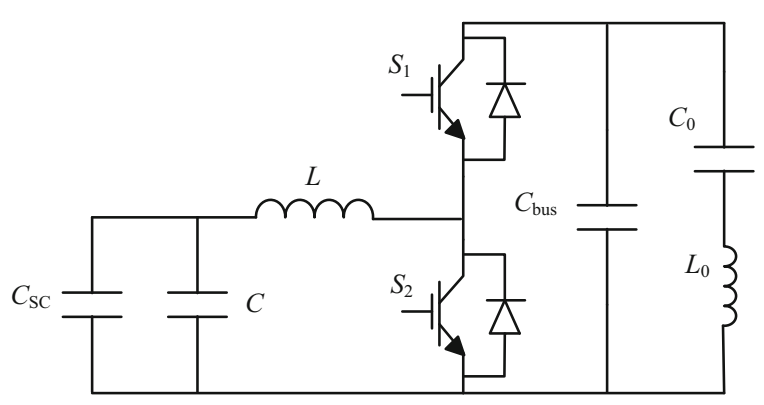

Fig. 3 Boost/buck converter

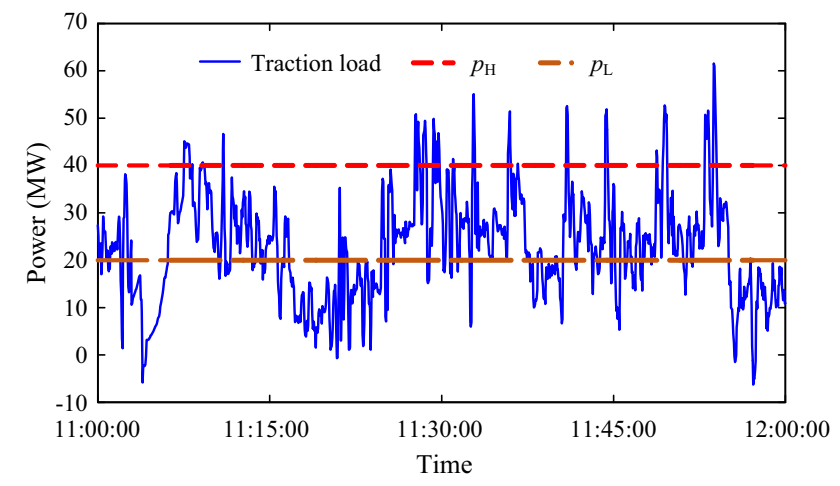

Fig. 4 An actual load power profile of a feeder

$w=\int_{t_{1}}^{t_{2}} p(t) \mathrm{d} t$.

With the help of ESS, the electric energy can be redistributed in time dimension. The objective of energy management in this work is to smooth grid-side power and re-utilize RB energy. As an example, in Fig. 4 we can preset power upper and lower limits denoted as $p_{\mathrm{H}}$ and $p_{\mathrm{L}}$ and assume that $p_{\text {load }}>p_{\mathrm{H}}$ denotes a peak, and accordingly, $p_{\text {load }}<p_{\mathrm{L}}$ a valley. Hence, the energy storage devices should charge and store energy during valley and $\mathrm{RB}$, and discharge and release energy during peak time. If the gross electric quantity in peak time is smaller than that in valley time, the peak part can be shaved and the valley part can be filled.

\subsubsection{Energy management}

The energy storage system uses the super capacitor for its rapid charging and high-power discharging in all working conditions. To ensure the safe operation of a super capacitor, when the state of charge $\left(S_{\mathrm{c}}\right)$ is under $S_{\mathrm{L}}$, which is set to avoid out-of-control of discharge, the super capacitor stops discharging. Similarly, when $S_{\mathrm{c}}$ is beyond $S_{\mathrm{H}}$, which is set to avoid out-of-control of charge, the super capacitor stops charging. Commonly, there are only two conditions in the process of operation: traction and RB. In order to cooperate with ESS, the system operation is reclassified into four modes.

- Traction mode

When $p_{\mathrm{L}}<p_{\text {load }}<p_{\mathrm{H}}$ or $S_{\mathrm{c}}$ is out of the boundary, the AC-DC converter only transfers reactive power; meanwhile, the super capacitor affords the voltage stabilization on the DC side as the DC-DC converter operates as a boost circuit.

- RB mode 


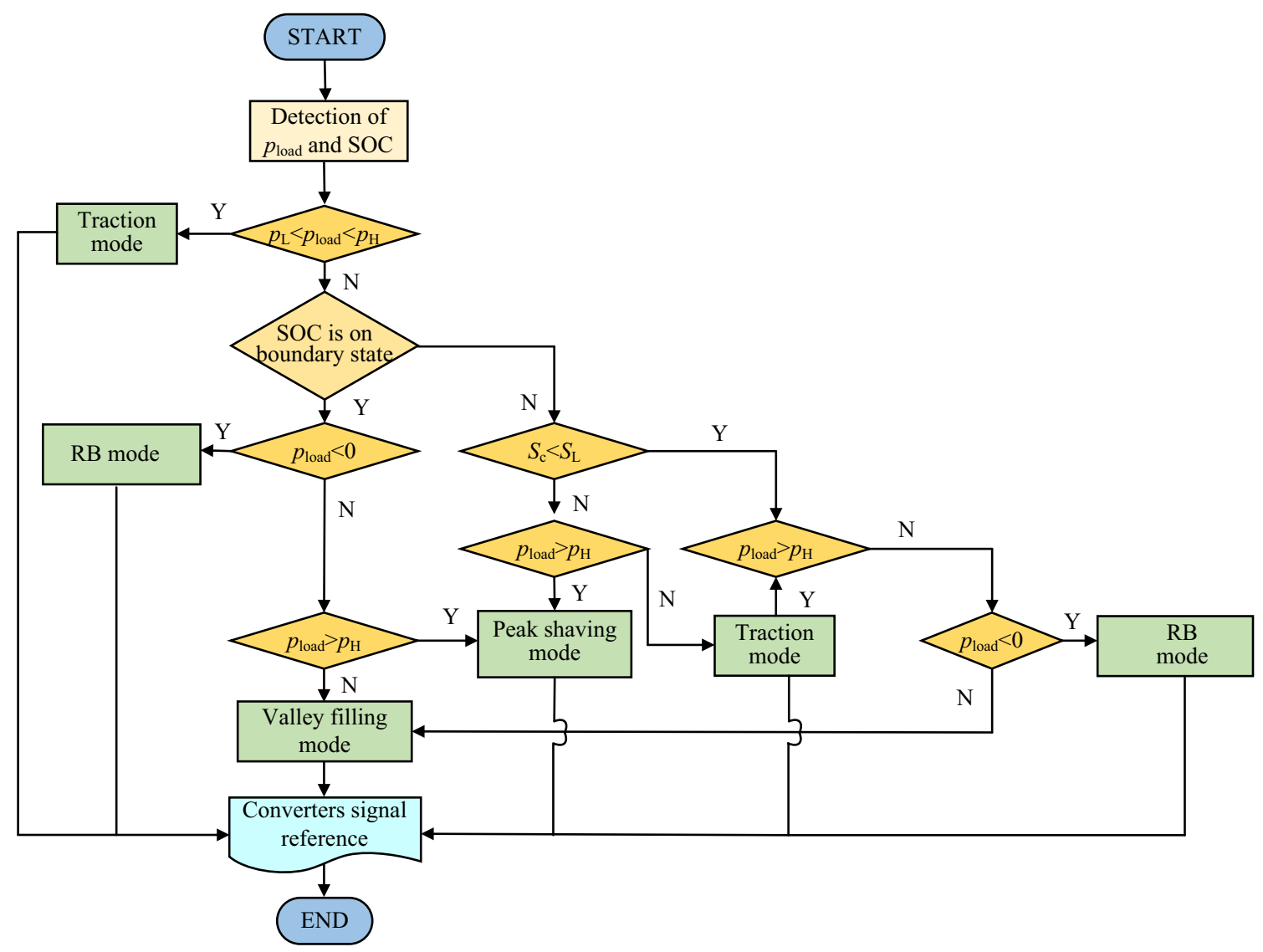

Fig. 5 Upper level control of CSS_SC

When $p_{\text {load }}<0$ and $S_{\mathrm{c}}<S_{\mathrm{H}}$, RB energy is absorbed partially or even fully by the super capacitor according to the given power $p_{\text {req. }}$. When $p_{\text {load }}<0$ and $S_{\mathrm{c}} \geq \mathrm{S}_{\mathrm{H}}$, RB energy is directly returned to the grid.

- Peak shaving mode

When $p_{\text {load }}>p_{\mathrm{H}}$ and $S_{\mathrm{c}}>\mathrm{S}_{\mathrm{L}}$, super capacitor begins to discharge to shave the peak of the load power with the help of boost circuit.

- Valley filling mode

When $0<p_{\text {load }}<p_{\mathrm{L}}$ and $S_{\mathrm{L}}<S_{\mathrm{c}}<S_{\mathrm{H}}$, the super capacitor begins to charge from the grid and fill the valley of the load power with the help of buck circuit.

In summary, after presetting $S_{\mathrm{L}}, S_{\mathrm{H}}$ and detecting $p_{\text {load }}$, $S_{\mathrm{c}}$ in real time, the working mode can be obtained by the algorithm in Fig. 5.

\subsubsection{Power flow and compensation direction}

With regard to the system operation, the power flow and compensation direction of four working modes are illustrated in Fig. 6, where the red arrow represents power flow and the yellow arrow compensation direction. In the following equations, $p_{\mathrm{s}}$ is grid output power, and $p_{\mathrm{sc}}$ is power absorbed by super capacitor.

In traction mode,

$p_{\mathrm{s}}=p_{\text {load }}$.

In regenerative braking mode,

$p_{\text {load }}=p-p_{\text {sc }}$.

In peak shaving mode,

$p_{\text {load }}=p_{\mathrm{s}}-p_{\mathrm{sc}}$.

In valley filling mode,

$p_{\mathrm{s}}=p_{\text {load }}+p_{\mathrm{sc}}$.

\subsection{Analysis of negative sequence compensation}

Based on KVL (Kirchhoff's voltage law) and KCL (Kirchhoff's current law), the compensation value is analyzed.

Assume that the three-phase voltages on the grid-side balance and negative sequence are completely 


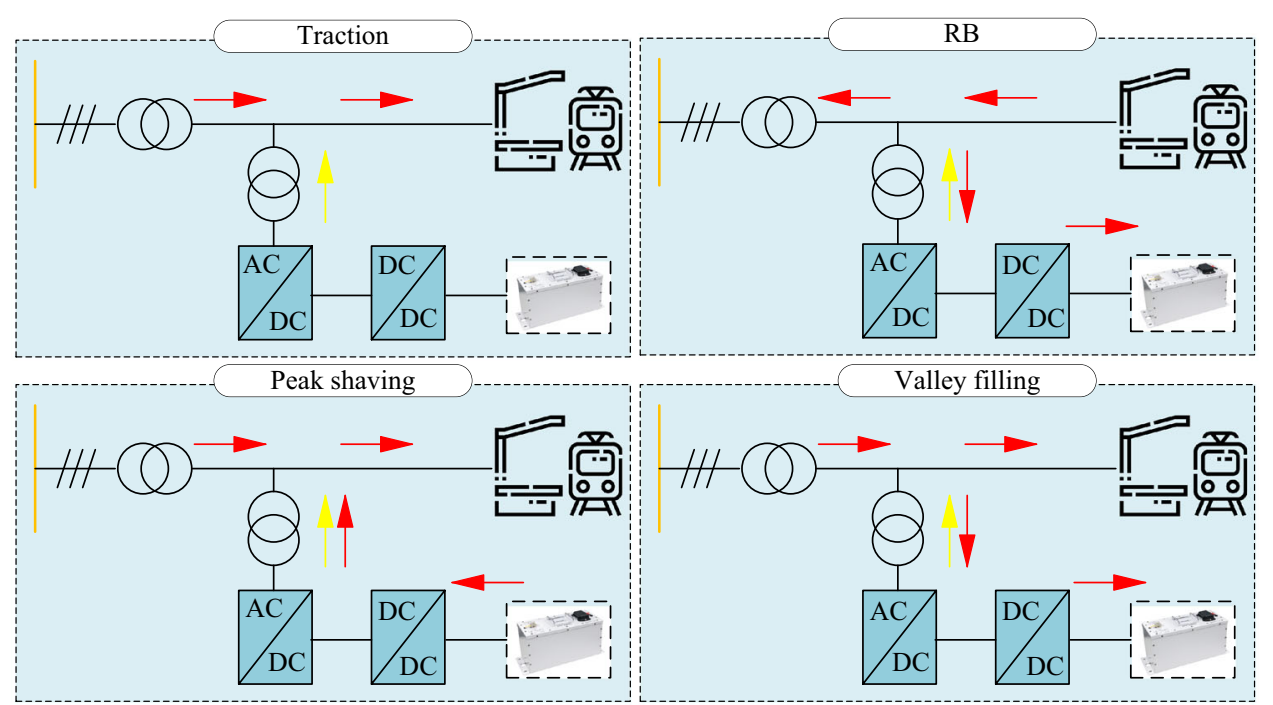

Fig. 6 Power flow and compensation direction

compensated. The voltages on the secondary side of threephase transformer are defined as

$$
\left\{\begin{array}{l}
v_{\mathrm{a}}=\sqrt{2} V_{\mathrm{a}} \cos (\omega t+\varphi), \\
v_{\mathrm{b}}=\sqrt{2} V_{\mathrm{b}} \cos \left(\omega t+\varphi-\frac{2}{3} \pi\right), \\
v_{\mathrm{c}}=\sqrt{2} V_{\mathrm{c}} \cos \left(\omega t+\varphi+\frac{2}{3} \pi\right),
\end{array}\right.
$$

where $V_{\mathrm{a}}=V_{\mathrm{b}}=V_{\mathrm{c}}$, and they are the RMS (root-meansquare values) of the three-phase voltages.

With the output power $p_{\mathrm{s}}$, the RMS value of secondary winding current $I_{\mathrm{a}}$ can be expressed as

$I_{\mathrm{a}}=\frac{p_{\mathrm{s}}}{3 V_{\mathrm{a}} \cos \varphi_{0}}$,

where $\cos \varphi_{0}$ is the system power factor near to 1 because of the utilization of $\mathrm{AC}$ locomotives.

According to the phase relation, the phase angle of $I_{\mathrm{a}}$ can be expressed as

$\varphi_{\mathrm{a} 1}=\varphi-\varphi_{0}$.

When the negative sequence current is perfectly compensated, i.e., the output currents manifest threephase symmetry, the output currents of secondary winding can be expressed as

$$
\left\{\begin{array}{l}
i_{\mathrm{a}}=\sqrt{2} I_{\mathrm{a}} \cos \left(\omega t+\varphi_{\mathrm{a} 1}\right), \\
i_{\mathrm{b}}=\sqrt{2} I_{\mathrm{b}} \cos \left(\omega t+\varphi_{\mathrm{a} 1}-\frac{2}{3} \pi\right) \\
i_{\mathrm{c}}=\sqrt{2} I_{\mathrm{c}} \cos \left(\omega t+\varphi_{\mathrm{a} 1}+\frac{2}{3} \pi\right)
\end{array} .\right.
$$

Finally, the compensation currents can be obtained with load current $i_{\text {load }}$ :

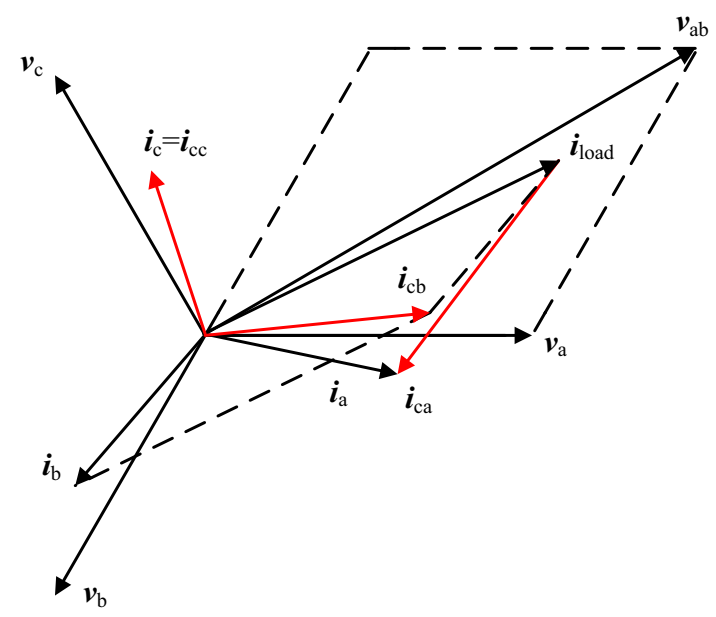

Fig. 7 Phasor diagram corresponding to traction, peak shaving and valley filling conditions

$\left\{\begin{array}{l}i_{\mathrm{ca}}=i_{\mathrm{a}}-i_{\text {load }}, \\ i_{\mathrm{cb}}=i_{\mathrm{b}}+i_{\text {load }}, \\ i_{\mathrm{cc}}=i_{\mathrm{c}} .\end{array}\right.$

When $v_{\mathrm{a}}$ is a reference, the phasor diagram of the compensation currents in the conditions of traction and peak shaving and valley filling is plotted in Fig. 7, and the phasor diagram of the compensation currents under RB is depicted in Fig. 8. 


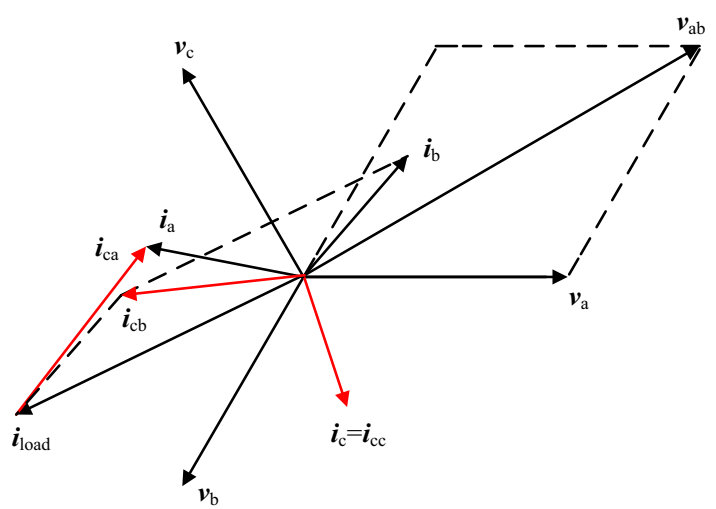

Fig. 8 Phasor diagram under RB

\section{Control strategies}

In this section, we focus on the control of converters. The general control scheme as shown in Fig. 9 can be divided into four parts. The instantaneous reactive power theory is employed to calculate the reactive power and harmonics values. The voltage loop keeps DC bus stable. Besides, the feedforward control and power loop regulate the behavior of the super capacitor.

\subsection{Control strategy of AC-DC converter}

In order to adapt to the proposed connecting mode, a coordinated control strategy of the AC-DC converter is designed and presented in Fig. 10, which enables the threephase AC system to accurately extract the fundamental wave component from single-phase load with use of the instantaneous reactive power theory. The proposed control strategy can meet the requirements of four conditions and realize active, reactive power compensation and harmonic suppression.

Calculating instantaneous symmetrical component is to convert the single-phase load current into the three-phase fundamental wave component, i.e., to formulate positive sequence component with three-phase instantaneous values:

$i_{\mathrm{a} 1}=\frac{1}{3}\left[i_{\mathrm{a}}(t)-\frac{1}{2} i_{\mathrm{b}}(t)-\frac{1}{2} i_{\mathrm{c}}(t)\right]+\frac{\sqrt{3}}{6 \omega} \times \frac{\mathrm{d}\left[i_{\mathrm{b}}(t)-i_{\mathrm{c}}(t)\right]}{\mathrm{d} t}$,

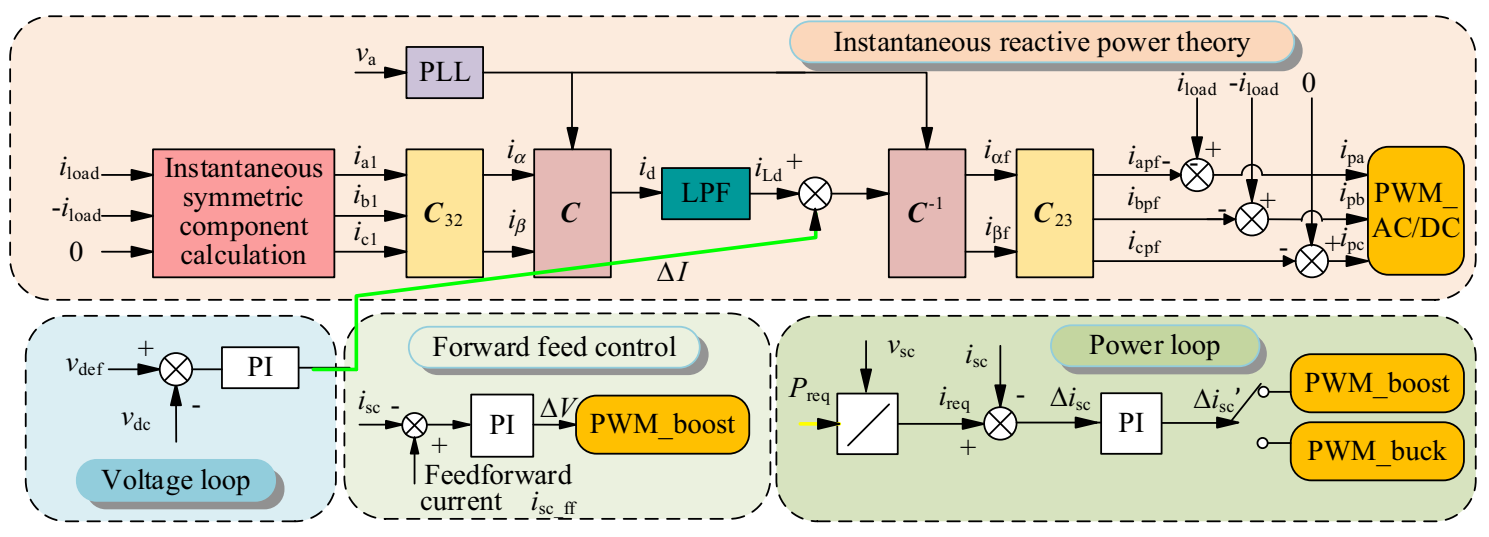

Fig. 9 General control scheme

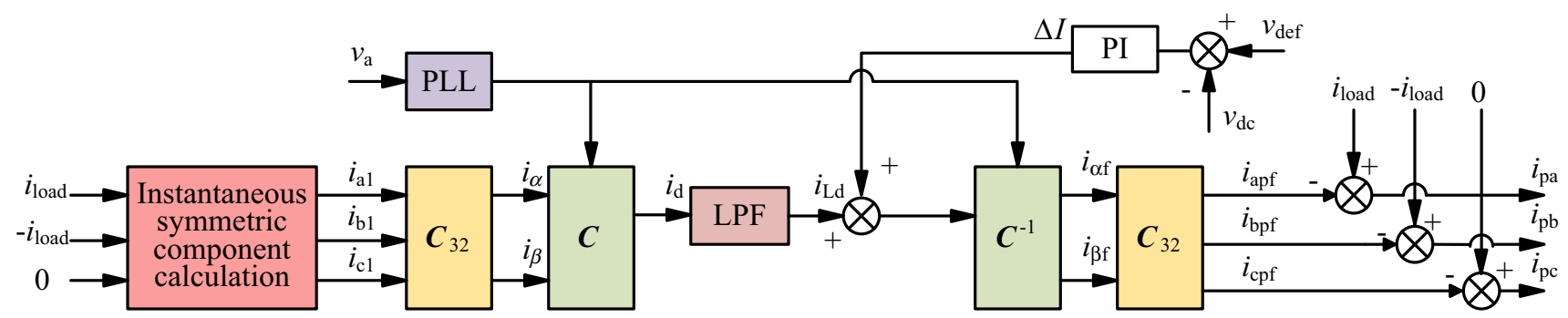

Fig. 10 Coordinated control strategy of AC-DC converter 
$i_{\mathrm{b} 1}=\frac{1}{3}\left[i_{\mathrm{b}}(t)-\frac{1}{2} i_{\mathrm{c}}(t)-\frac{1}{2} i_{\mathrm{a}}(t)\right]+\frac{\sqrt{3}}{6 \omega} \times \frac{\mathrm{d}\left[i_{\mathrm{c}}(t)-i_{\mathrm{a}}(t)\right]}{\mathrm{d} t}$,

$i_{\mathrm{c} 1}=\frac{1}{3}\left[i_{\mathrm{c}}(t)-\frac{1}{2} i_{\mathrm{a}}(t)-\frac{1}{2} i_{\mathrm{b}}(t)\right]+\frac{\sqrt{3}}{6 \omega} \times \frac{\mathrm{d}\left[i_{\mathrm{a}}(t)-i_{\mathrm{b}}(t)\right]}{\mathrm{d} t}$,

where $i_{\mathrm{a} 1}, i_{\mathrm{b} 1}$ and $\mathrm{i}_{\mathrm{c} 1}$ are positive sequence components; $i_{\mathrm{a}}(t), i_{\mathrm{b}}(t)$ and $i_{\mathrm{c}}(t)$ are instantaneous load currents.

Then, the instantaneous active current can be obtained through Clark's transformation and Park's transformation. The corresponding transformation matrix $\boldsymbol{C}_{32}$ and $\boldsymbol{C}$ is

$\boldsymbol{C}_{32}=\sqrt{\frac{2}{3}}\left[\begin{array}{ccc}1 & -\frac{1}{2} & -\frac{1}{2} \\ 0 & \frac{\sqrt{3}}{2} & -\frac{\sqrt{3}}{2}\end{array}\right]$,

$\boldsymbol{C}=\left[\begin{array}{cc}\sin \omega t & -\cos \omega t \\ -\cos \omega t & -\sin \omega t\end{array}\right]$.

And the DC component of $i_{\mathrm{d}}$ can be acquired by LPF (low-pass filter).

It is clear that the voltage loop in Fig. 10 is designed to make DC bus voltage stable. The master control strategy is based on the traditional instantaneous reactive power theory, which is widely used in APF (active power filter) control strategy.

\subsection{Control strategy of DC-DC converter}

The control strategy of the DC-DC converter under different working conditions is based on two methods.

When the system only runs in traction, a load current feedforward control [23] can realize the stability of DC bus voltage and the fast tracking of instructions. The block

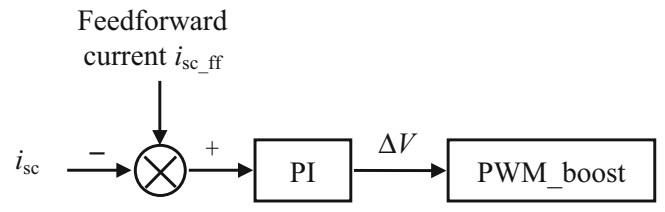

Fig. 11 Load current feedforward control

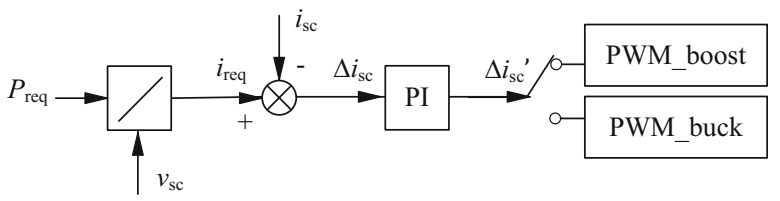

Fig. 12 Power loop control diagram is shown in Fig. 11. The key point of this method is to keep the energy into/out the super capacitor while maintaining the stability of DC bus voltage.

When the system works under RB, peak shaving and valley filling conditions, the control strategy of the DC-DC converter as shown in Fig. 12 is based on deviation value between the output current of super capacitor $i_{\mathrm{sc}}$ and expected current $i_{\text {req }}$ that is calculated by $P_{\text {req }}$ and $V_{\text {sc }}$.

$P_{\text {req }}$, a key factor to control the amount of power transferred, is obtained by

$\left\{\begin{array}{l}P_{\text {req }}=p_{\text {load }}<0, \quad \text { for } \mathrm{RB} \\ P_{\text {req }}=p_{\text {load }}-p_{\mathrm{H}}, \quad \text { for peak shaving } \\ P_{\text {req }}=p_{\mathrm{L}}-p_{\text {load }}, \quad \text { for valley filling }\end{array}\right.$

\section{Simulation analysis}

\subsection{Simulation design}

To verify the feasibility of proposed system and its control strategy, a train is simulated by a controlled current source block whose specifications refer to mass measurement data. Load current $i_{\text {load }}$ is given as

$i_{\text {load }}(t)= \begin{cases}i_{1}(t), & \text { for traction and peak shaving } \\ i_{2}(t), & \text { for RB } \\ 0.5 i_{1}(t), & \text { for valley filling }\end{cases}$

$$
\begin{aligned}
i_{1}(t)= & 384 \sin (\omega t)+8 \sin \left(3 \omega t-30^{\circ}\right)+5 \sin \left(5 \omega t+15^{\circ}\right) \\
& +4 \sin \left(7 \omega t+60^{\circ}\right)+4 \sin \left(45 \omega t-60^{\circ}\right) \\
& +8 \sin \left(47 \omega t+50^{\circ}\right)+6 \sin (49 \omega t)(\mathrm{A}),
\end{aligned}
$$

$i_{2}(t)=-0.5 i_{1}(t)$.

For AC-DC-AC locomotives, the power factor is near \pm 1 . Similarly, the simulation can be simplified with

Table 1 Simulation parameters

\begin{tabular}{lll}
\hline Parameters & Values & Unit \\
\hline Rated source voltage & 27.5 & $\mathrm{kV}$ \\
Rated grid frequency & 50 & $\mathrm{~Hz}$ \\
Grid impedance & 1 & $\Omega$ \\
Transformer & $10: 1$ & - \\
Output inductor at AC side & 0.07 & $\mathrm{mH}$ \\
Output impendence at AC side & 1 & $\Omega$ \\
DC bus voltage & 6 & $\mathrm{kV}$ \\
DC bus capacitor & 50 & $\mu \mathrm{F}$ \\
Boost/buck circuit inductor & 1 & $\mathrm{mH}$ \\
Capacitance of super capacitor & 3000 & $\mathrm{~F}$ \\
Rated voltage of super capacitor & 2700 & $\mathrm{~V}$ \\
$p_{\mathrm{H}}$ & 6 & $\mathrm{MW}$ \\
$p_{\mathrm{L}}$ & 5 & $\mathrm{MW}$ \\
\hline
\end{tabular}


Table 2 Simulation cases

\begin{tabular}{llcl}
\hline Time $(\mathrm{s})$ & Mode & $p_{\text {load }}(\mathrm{MW})$ & Detail \\
\hline $0-1$ & Traction & 5.45 & $\begin{array}{c}\text { Avoid uncontrollable } \\
\text { discharging }\end{array}$ \\
& & -3.23 & Fully absorbed by ESS \\
$1-2$ & RB & 6.45 & Fully shave \\
$2-3$ & Peak shaving & 7.70 & Partially shave \\
$3-4$ & Peak shaving & 3.45 & Fill to the set value \\
$4-5$ & Valley filling & & \\
\hline
\end{tabular}

$27.5 \mathrm{kV}$ three-phase voltage as the sources. Other simulation parameters are listed in Table 1.

In order to exhibit the dynamic performance of the proposed system, there are five working cases for the time horizon of $5 \mathrm{~s}$, with each case of $1 \mathrm{~s}$ (see Table 2). Peak shaving has two different settings of $P_{\text {req, }}$ which are 6.45 MW for fully shaving and $2.2 \mathrm{MW}$ for partially shaving.

On all conditions, it is important for the power quality to meet the standards in terms of the three-phase voltage unbalance, harmonics and power factor, as well as the stability of DC side voltage.

\subsection{Simulation results}

Figure 13 shows three-phase voltage and current at the primary side in simulation and the a-phase amplification diagrams. Figure 14 depicts the three-phase voltage unbalance, DC bus voltage, power and SOC of super capacitor, respectively. In Fig. 13, the three-phase voltage and current are symmetrical sine waves, respectively. In Fig. 14b, DC bus voltage is settled around $6 \mathrm{kV}$. As for harmonics, THD (total harmonic distortion) of the system is given in Table 3.

\section{A. Simulation of traction condition}

As Fig. 14a indicates, the unbalance fluctuation of the three-phase voltage is around $0.005 \%$, far lower than the standard maximum allowable value of $1.3 \%$. Moreover, in Fig. $14 \mathrm{c}, \mathrm{d}$, the DC bus voltage reaches and remains to be steady state, $6 \mathrm{kV}$, while the SOC of the super capacitor is nearly unchanged. It is apparent that CSS_SC only performs power quality maintenance in this case.

B. Simulation of RB condition

The active power of the equivalent load $p_{\text {load }}$ is roughly - 3.23 MW, which is also RB power in 1-2 s. In Fig. 14c, the active power of the super capacitor $p_{\mathrm{sc}}$ is $2.8 \mathrm{MW}$ and the active power of $0.43 \mathrm{MW}$ is feed back to the grid. Meanwhile, the three-phase voltage is fluctuating around $0.0035 \%$, which is within the standard range. Note that the super capacitor is charging with SOC rising from $70.265 \%$ to $70.42 \%$ in one second. In this cases, the power factor reaches to -1 . As a result, the RB energy is almost fully absorbed by the super capacitor.

\section{Simulation of peak shaving}

To demonstrate that the system is flexible to deal with both high-power and low-power loads, peak shaving condition is simulated twice (2-3 s and 4-5 s). During 2-3 s, the traction power, $6.45 \mathrm{MW}$, is almost fully supplied by

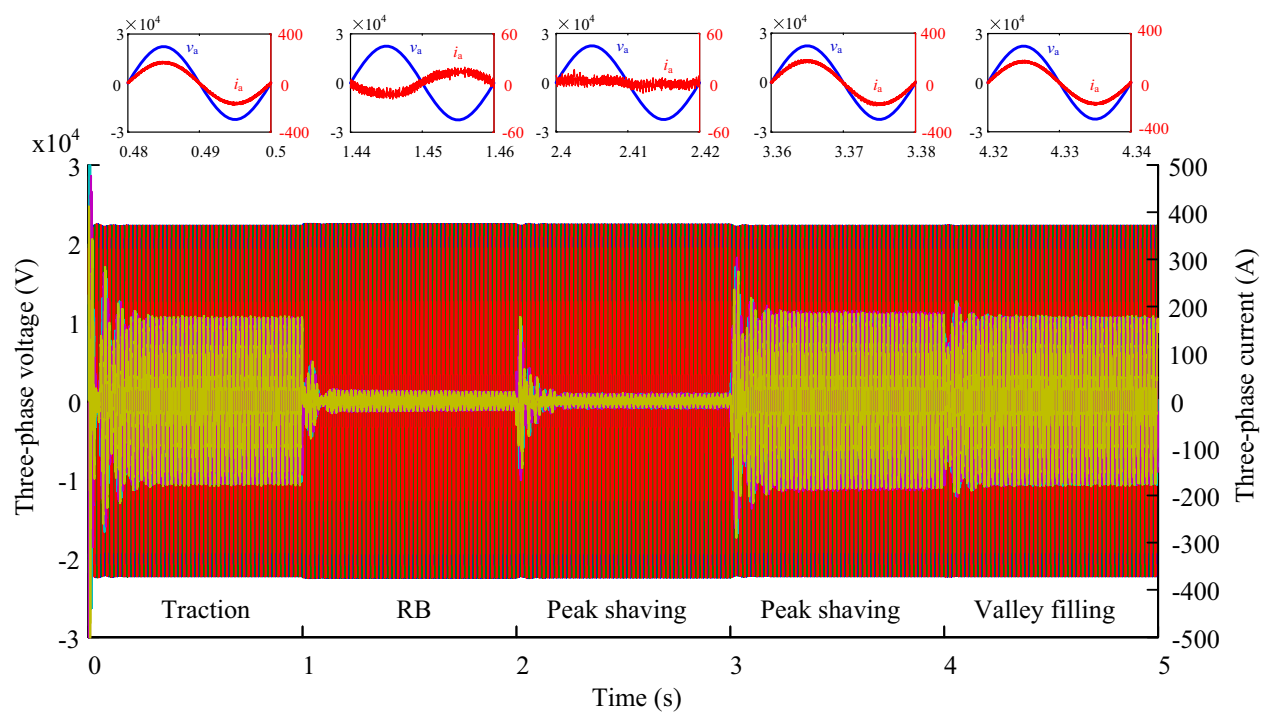

Fig. 13 Three-phase voltage and current 


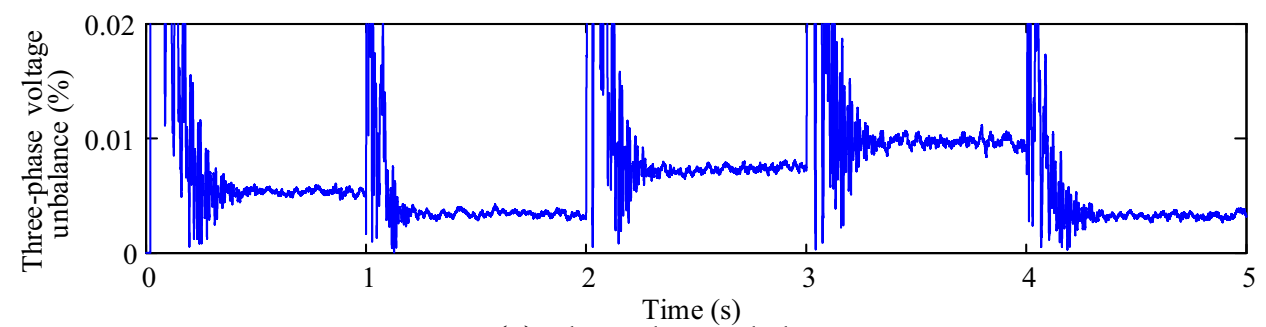

(a) Three-phase unbalance

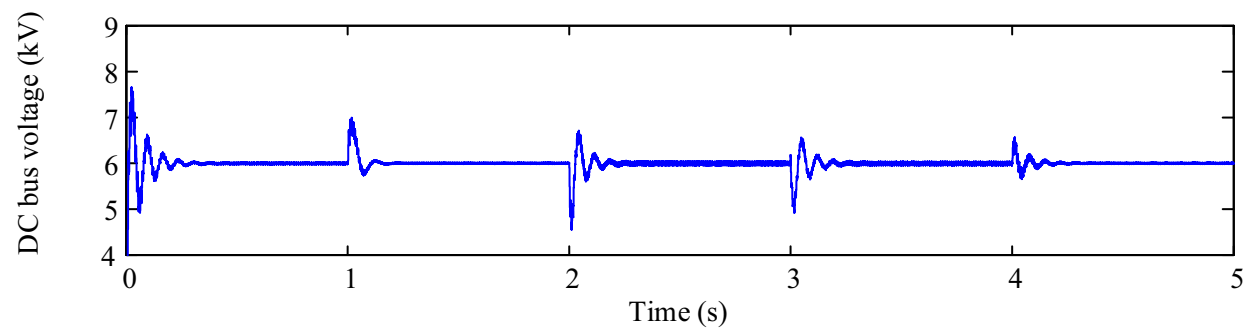

(b) DC-side voltage

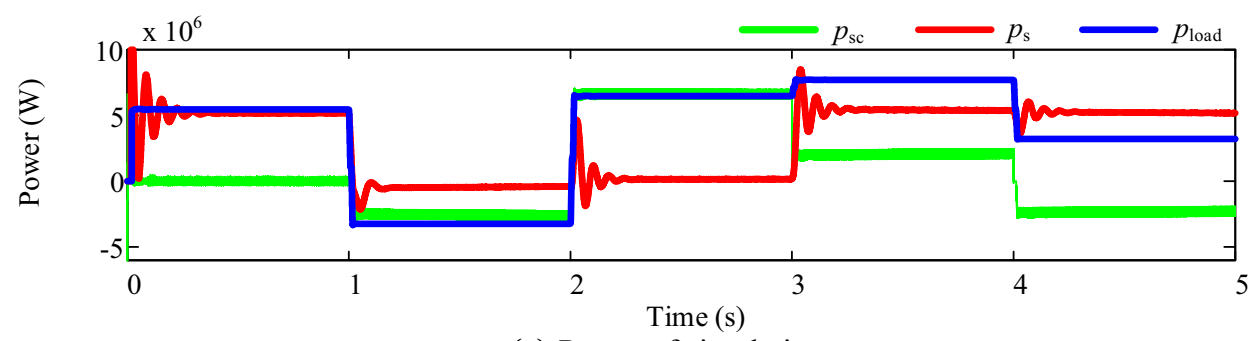

(c) Power of simulation

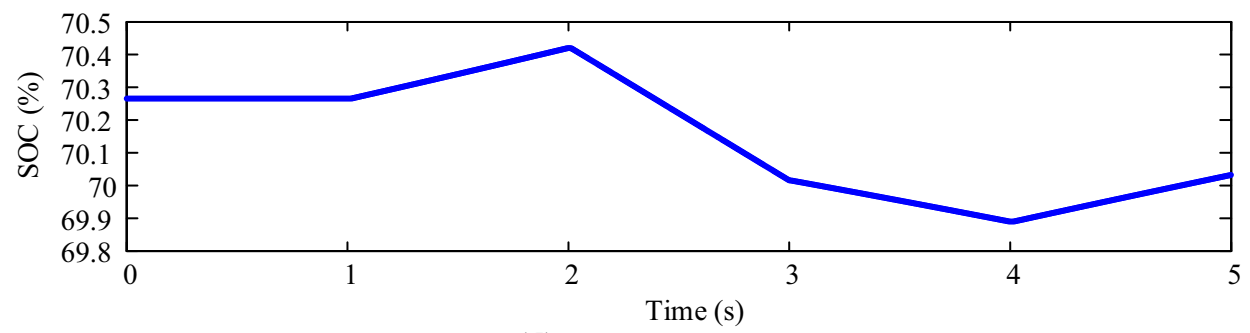

(d) SOC of super capacitor

Fig. 14 Simulation results in traction, RB, peak shaving and valley filling conditions

Table 3 THD of the system

\begin{tabular}{lll}
\hline Time $(\mathrm{s})$ & Mode & THD $(\%)$ \\
\hline $0-1$ & Traction & 2.42 \\
$3-4$ & Peak shaving & 2.69 \\
$4-5$ & Valley filling & 2.28 \\
\hline
\end{tabular}

the super capacitor, while the three-phase voltage unbalance is approximately between $0.007 \%$ and $0.008 \%$ and the SOC is from $70.42 \%$ to $70.015 \%$. During $3-4 \mathrm{~s}$, the required energy to propel the vehicle, $p_{\text {load}}$, is roughly equal to the sum of the super capacitor discharge power, $p_{\text {sc }}$, and grid output power, $p_{\mathrm{s}}$, as shown in Fig. $14 \mathrm{c}$, where $p_{\text {load }}, p_{\mathrm{sc}}$ and $p_{\mathrm{s}}$ are about $5.5,2.2$ and $7.7 \mathrm{MW}$, respectively. The initial value of SOC with $70.015 \%$ falls to $69.89 \%$. The result shows that the control strategy of CSS_SC is flexible to manage power flow.

D. Simulation of valley filling

On the premise that three-phase voltage unbalance is within standard, during 4-5 s, the system is effective in filling valley, which can be seen in Fig. 14a-d. In Fig. 14c, the grid power $p_{\mathrm{s}}=5.45 \mathrm{MW}$, equals to the sum of the absorbing power of super capacitor, $p_{\mathrm{sc}}=-2 \mathrm{MW}$, and the total load power, $p_{\text {load }}=3.45 \mathrm{MW}$. In the meantime, 


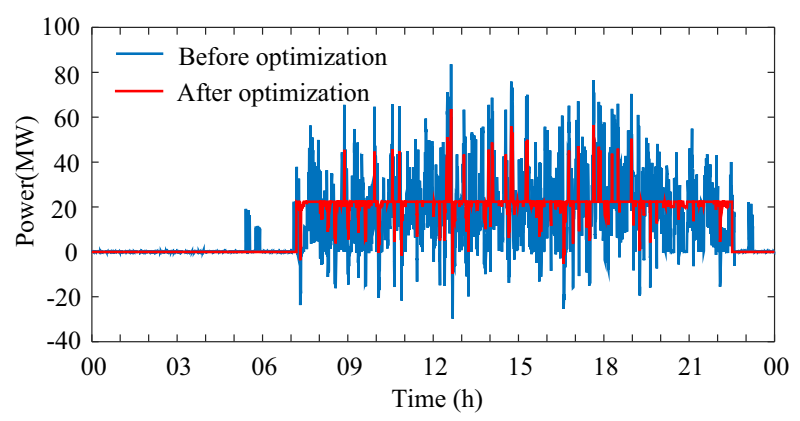

(a) Power before and after optimization

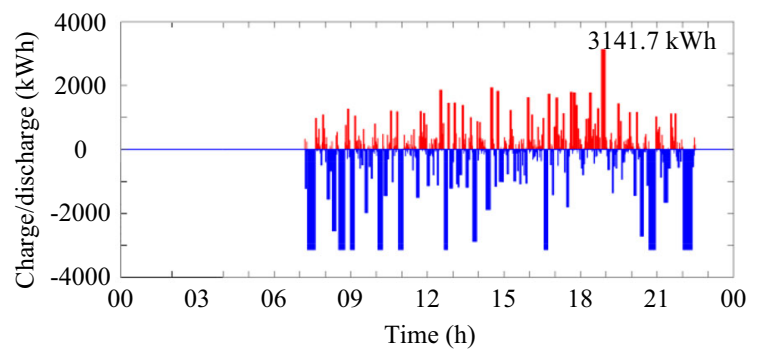

(b) Action of energy storage device

Fig. 15 Power fluctuation optimization at Danyang traction station

the super capacitor is charging with the SOC from $69.89 \%$ to $70.032 \%$.

In conclusion, the simulations demonstrate that the CSS_SC can handle the fundamental functions of adjusting power quality and energy transferring. In addition, the performance of smoothing grid power fluctuation during $3-5 \mathrm{~s}$ is shown in Fig. $14 \mathrm{c}$, where the blue line $\left(p_{\text {load }}\right)$ is adjusted into the horizontal red line $\left(p_{\mathrm{s}}\right)$ with the help of super capacitor.

\section{Case study}

In this section, the performance of smoothing power fluctuation on the grid side is tested. The raw data are collected from Danyang traction substation in Jiangsu, China. The specifications of ESS are set as $20 \mathrm{MW}$ in power and $3200 \mathrm{~kW} \mathrm{~h}$ in capacity. The triggered value of peak shaving and valley filling is set as $22.4 \mathrm{MW}$. The simulation results of power diagram before and after optimization are shown in Fig. 15a, and the action of charging/discharging is shown in Fig. 15b.

The characteristic of power diagram has been illustrated in Sect. 2. In Fig. 15a, before optimization, the trains intensively run across this power supply zone from 7:05 to 23:14. By applying proposed CSS_SC, the optimized power profile (the red line in Fig. 15a) is smoother. It is interesting to note that after optimization, the daily load factor $\gamma$ increases by $17.9 \%$, with the minimum load rate $\beta$ also increasing by $20.3 \%$. The gap of valley to peak is shrunk by $40 \mathrm{MW}$, while the rate of valley to peak is reduced by $20.3 \%$.

$\gamma=\frac{p_{\text {av_per }}}{p_{\text {max } \_ \text {per }}}$,

$\beta=\frac{p_{\text {min_per }}}{p_{\text {max } \_ \text {per }}}$,

where $p_{\text {av_per }}$ is daily average load power, $p_{\text {max } \_ \text {per }}$ is daily maximum load power and $p_{\text {min_per }}$ is daily minimum load power.

In Fig. 15b, the width of the red/blue bars represents the charging/discharging time of the super capacitor, and the height of the red/blue bars represents the charging/discharging energy of the super capacitor. It is counted that the total number of discharging cycles is 524 and the maximum discharge volume is $3141.7 \mathrm{kWh}$. The peak can be fully shaved only if the charging part is larger than discharging part. The statistics show that the utilized RB energy is $8040.8 \mathrm{kWh}$, while daily consumption is $318000 \mathrm{kWh}$. It is found out that the total energy of peak shaving is $122658.3 \mathrm{kWh}$, which contributes to the stability of the grid power.

\section{Conclusions}

In this work, we focus on improving energy efficiency and address power quality problems for an optimized energy management with a proposed new topology of ERSs. In a purpose to realize economic energy saving and smooth power fluctuation, CSS_SC is proved to be flexible to work in four conditions by using the coordinated control strategy. In summary, the advantages of CSS_SC are listed as follows:

- The distance of power supply is extended, and the speed of trains is increased due to the removal of the neutral section for the traction substation.

- The RB energy of trains can be temporarily stored for reusing in traction. Therefore, the drastic fluctuation of load power on the power grid is weakened and the load rate of transformers is promoted.

- The regulated power quality can be guaranteed even in $\mathrm{RB}$ condition. The AC-DC converter keeps managing the power quality in terms of voltage, current and power. Power compensation is realized by generating required active and reactive power with assistance from the energy storage device.

- The system with energy storage device is suitable to unstable renewable energy. Bidirectional DC-DC converter can play a role of energy management and 
coordination between the renewable energy and energy storage devices.

Open Access This article is licensed under a Creative Commons Attribution 4.0 International License, which permits use, sharing, adaptation, distribution and reproduction in any medium or format, as long as you give appropriate credit to the original author(s) and the source, provide a link to the Creative Commons licence, and indicate if changes were made. The images or other third party material in this article are included in the article's Creative Commons licence, unless indicated otherwise in a credit line to the material. If material is not included in the article's Creative Commons licence and your intended use is not permitted by statutory regulation or exceeds the permitted use, you will need to obtain permission directly from the copyright holder. To view a copy of this licence, visit http://creativecommons. org/licenses/by/4.0/.

\section{References}

1. Li Q (2016) Industrial frequency single-phase AC traction power supply system for urban rail transit and its key technologies. J Mod Transport. https://doi.org/10.1007/s40534-016-0097-3

2. Hu H, Zheng Z (2018) The framework and key technologies of traffic energy internet. Proc CSEE 1:12-24 (in Chinese)

3. Adinolfi A, Lamedica R, Modesto C, Prudenzi A, Vimercati S (1998) Experimental assessment of energy saving due to trains regenerative braking in an electrified subway line. IEEE Trans Power Deliv 4(13):1536-1542

4. González-Gil A, Palacin R, Batty P (2013) Sustainable urban rail systems: strategies and technologies for optimal management of regenerative braking energy. Energy Convers Manag. https://doi. org/10.1016/j.enconman.2013.06.039

5. Li Q, Wang X, Huang X et al (2019) Research on flywheel energy storage technology for electrified railway. Proc CSEE 39(7):2025-2033 (in Chinese)

6. Hernandez JC, Sutil FS (2016) Electric vehicle charging stations feeded by renewable: PV and train regenerative braking. IEEE Latin America Trans 14(7):3262-3269

7. Fan Q, Wu S, Zhang Y et al (2019) Research on MMC-based regenerative braking energy recovery device for railways. Electr Autom 41(1):99-101+107 (in Chinese)

8. Yang X, Li X, Gao Z, Wang H, Tang T (2013) A cooperative scheduling model for timetable optimization in subway systems. IEEE Trans Intell Transp Syst 1:438-447

9. Nasri A, Moghadam MF, Mokhtari H (2010) Timetable optimization for maximum usage of regenerative energy of braking in electrical railway systems. SPEEDAM, Proc. https://doi.org/10. 1109/SPEEDAM.2010.5542099

10. Yang X, Chen A, Li X, Ning B, Tang T (2015) An energyefficient scheduling approach to improve the utilization of regenerative energy for metro systems. Transp Res C Emerg Technol. https://doi.org/10.1016/j.trc.2015.05.002

11. Hu J, Zhao Y, Liu X (2008) The design of regeneration braking system in light rail vehicle using energy-storage Ultra-capacitor. In: 2008 IEEE vehicle power and propulsion conference, pp 1-5

12. Chen H, Che Y, Fu R, Wang X, Lv X, Zhu H (2018) Study on regenerative braking energy utilization and power quality control in electrified railways. In: 2018 IEEE international power electronics and application conference and exposition (PEAC), pp 1-6

13. Wu M (2018) Back-to-back PV generation system and its control strategy for electrified railway. Power Syst Technol 2:541-547 (in Chinese)

14. Aguado JA, Sánchez Racero AJ, de la Torre S (2018) Optimal operation of electric railways with renewable energy and electric storage systems. IEEE Trans Smart Grid 2(9):993-1001

15. Xie S (2018) Influence of PV generation system accessing to traction power supply system on power quality. Electr Power Autom Equip 10:53-59 (in Chinese)

16. Li Q (2014) On new generation traction power supply system and its key technologies for electrification railway. J Southwest Jiaotong Univ 4:559-568 (in Chinese)

17. He X, Ren H (2019) Power flow analysis of the advanced cophase traction power supply system. Energies. https://doi.org/10. 3390/en 12040754

18. Chen M et al (2016) Modelling and performance analysis of advanced combined co-phase traction power supply system in electrified railway. IET Gener Transm Distrib 4(10):906-916

19. He J (2005) Reasonable selection of capacity of traction transformer. Electric Railway 6:1-5

20. Technical specification of traction transformer for AC electrified railways, TB/T 3159-2007[S], China, August (2007)

21. Brisset S, Ogoer M (2017) Collaborative and multilevel optimizations of a hybrid railway power substation. Int $\mathrm{J}$ Numer Model. https://doi.org/10.1002/jnm.2473

22. Deng W, Dai C (2019) Application of PV generations in AC/DC traction power supply system and the key problem analysis under the background of rail transit energy internet. Proc CSEE 2:541-547 (in Chinese)

23. Zhang X, Xu H, Guo Q, Zhao F (2011) A new control scheme for DC-DC converter feeding constant power load in electric vehicle. In: 2011 international conference on electrical machines and systems, pp 1-4 